erative apnoea in preterm infants. Anesthesiology 1987 ; 66: 483-8.

11 Welborn LG, Hannallah RS, Fink R, Ruttimann UE, Hicks $J M$. High-dose caffeine suppresses postoperative apnoea in former preterm infants. Anesthesiology 1989; 71: 347-9.

12 Newburger JW, Rosenthal A, Williams RG, et al. Noninvasive tests in the initial evaluation of heart murmurs in children. N Engl J Med 1983; 308: 61-3.

13 American Heart Association special report. Prevention of bacterial endocarditis. JAMA 1990; 264: 2919-22.

14 Chiang $T M$, Suskis AE, Ross DE. Tonsillectomy performed on an outpatient basis: report of a series of 40,000 cases performed without a death. Arch Otolaryngol Head Neck Surg 1968: 88: 307-9.

15 Maniglia AJ, Kushner H, Cozzi L. Adenotonsillectomy: a safe outpatient procedure. Arch Otolaryngol Head Neck Surg 1989; 115: 92-5.

\section{What are the problems in the recovery room?}

\author{
Bernard V. Wetchler MD \\ Division of Anesthesia, University of Illinois College of \\ Medicine at Peoria, Peoria, Illinois
}

Every outpatient facility must be able to limit the problems that cause unanticipated admissions to the hospital and they must have practical discharge criteria if patients are to go home in a timely fashion following outpatient surgery. As anaesthetists we have little or no control over the complications of surgery that cause admission to the hospital, but we can play a major role in limiting admissions due to pain, emesis and croup.

\section{Pain}

Postoperative pain control should be started intraoperatively by supplementing intravenous or inhalation anaesthesia with short-acting narcotic analgesics (alfentanil, fentanyl, sufentanil), a nonsteroidal anti-inflammatory drug (ketorolac) or local/ regional block. By making appropriate use of narcotic analgesics or local/regional block intraoperatively, awakening will be smoother and discharge home will occur sooner.

Postsurgical pain must be treated quickly and effectively. Medications given in the recovery room (RR) should be monitored closely and given in small, immediately
TABLE Paediatric recovery room pain control

\begin{tabular}{|c|c|c|}
\hline Drug & Dose & Route \\
\hline Fentanyl & $0.35-0.70 \mu \mathrm{g} \cdot \mathrm{kg}^{-1}$ & iv \\
\hline Alfentanil & $2-4 \mu \mathrm{g} \cdot \mathrm{kg}^{-1}$ & $i v$ \\
\hline Acetaminophen & $60 \mathrm{mg} \cdot \mathrm{yr}^{-1}$ & po \\
\hline $\begin{array}{l}\text { Acetaminophen } 120 \mathrm{mg}, \\
\text { codeine } 12 \mathrm{mg} \text {, elixir } 5 \mathrm{ml}\end{array}$ & $5-10 \mathrm{ml}$ & po \\
\hline Meperidine & $0.5 \mathrm{mg} \cdot \mathrm{kg}^{-1}$ & $i m$ \\
\hline Codeine & $1-1.5 \mathrm{mg} \cdot \mathrm{kg}^{-1}$ & $i m$ \\
\hline
\end{tabular}

effective intravenous doses. Intramuscular injection for pain control in the RR is probably more a custom than a thoroughly considered process.

At Methodist Ambulatory SurgiCare pain in both adults and children is managed with a short-acting narcotic analgesic (fentanyl, alfentanil). Fentanyl $12.5 \mu \mathrm{g}$ iv every five minutes up to a total dose of $50-75 \mu \mathrm{g}$ or alfentanil $50-75 \mu \mathrm{g}$ iv every two to three minutes up to a total dose of $200-300 \mu \mathrm{g}$ has proved to be very effective for the adult. Pain control for the paediatric patient will be found in the Table. Reuniting child with parent as soon as possible following entry into the RR helps to differentiate between crying from fright or crying from pain.

A decrease in pain, analgesic requirement, $R R$ sideeffects, earlier home readiness, and more rapid return to normal activity can be achieved by combining many simple (sensory) nerve blocks with intravenous or inhalation anaesthesia.

When the ilioinguinal and iliohypogastric nerves were infiltrated with bupivacaine during paediatric herniorrhaphy less codeine im was administered in the RR, less acetaminophen was required at home and a higher activity level was noted over the $\mathbf{4 8} \mathrm{hr}$ following surgery than in a control group. ${ }^{1}$ Lidocaine aerosolized into the surgical wound before closure in adult patients undergoing inguinal herniorrhaphy reduced pain after a single administration compared with untreated patients. ${ }^{2}$

Circumcision is a procedure that lends itself to local or regional supplementation: dorsal nerve block; topical anaesthesia (lidocaine spray, 10-20 mg of $10 \%$; lidocaine jelly, 0.5-1 ml of 2\%: lidocaine ointment, $0.5-1 \mathrm{ml}$ of $5 \%$ ); subcutaneous ring block with $0.25 \%$ bupivacaine provide effective pain control. ${ }^{3-5}$

Caudal block supplementation has been utilized to limit paediatric patients' postsurgical pain (circumcision, herniorrhaphy, hypospadias, orchiopexy). Whenever a caudal is administered for analgesia, care must be taken that motor strength is not compromised in an attempt to obtain pain control. There does not appear to be any advantage to using more concentrated solutions than $0.25 \%$ bupivacaine containing epinephrine $1: 200,000$. Wolf and coworkers noted that $0.0625 \%$ bupivacaine was ineffective for caudal analgesia. ${ }^{6}$ However, in a volume 
of $0.75 \mathrm{ml} \cdot \mathrm{kg}^{-1}, 0.125 \%$ bupivacaine (with epinephrine 1:200,000) provided equipotent analgesia and less motor blockade than $0.25 \%$ bupivacaine (with epinephrine $1: 200,000)$ in infants and children.

Postoperative morbidity following laparoscopic tubal sterilization varies, depending upon the type of sterilization performed: less pain and cramping following cautery than after Yoon fallopian ring sterilization. Infiltration of the mesosalpinx in the area of the Yoon ring placement with $0.5 \%$ bupivacaine at the conclusion of surgical sterilization decreases patient pain in the RR. ${ }^{7}$

At the present time, intra-articular bupivacaine (20-40 $\mathrm{ml}, 0.25 \%$ ) is a popular and safe method of providing pain relief after an arthroscopic procedure. Difference in pain intensity scores has not been demonstrated with consistency in the literature, but patients appear to ambulate more rapidly and have a shorter stay in the RR. Anecdotal comments favour the technique.

\section{Nausea and vomiting}

Contributing factors are pain, narcotic analgesic drugs, choice of anaesthetic technique or agents, operative procedure, sudden movement or position change, history of motion sickness, hypotension, obesity, day of menstrual cycle, and high oestrogen level.

\section{Pain}

A relationship between postoperative pain and the frequency of nausea in the early postsurgical period has been established. ${ }^{8}$ Relief of pain without relief of nausea was unusual regardless of the analgesic administered for pain control.

Opioid analgesics are highly effective both in preventing and treating postoperative pain. Controversy surrounds the use of narcotic analgesics in the ambulatory setting because they may increase postoperative nausea and vomiting. If a narcotic, nitrous oxide, anaesthetic is administered the occurrence of nausea and vomiting will be increased compared with an inhalation anaesthetic. 9,10 There are, however, a number of studies that conclude that a narcotic supplemented anaesthetic technique (fentanyl $1.5-2 \mu \mathrm{g} \cdot \mathrm{kg}^{-1} i v$ or alfentanil $6-8 \mu \mathrm{g} \cdot \mathrm{kg}^{-1} \mathrm{iv}$ ) results in earlier ambulation and discharge for the ambulatory surgery patient. ${ }^{11,12}$

Ketorolac, a nonsteroidal anti-inflammatory drug (NSAID) is a peripherally acting potent injectable analgesic associated with few central nervous system sideeffects. When compared to morphine or meperidine there is less dizziness, nausea and vomiting. ${ }^{13}$ Drowsiness is comparable to patients receiving placebo. Further studies are needed before valid conclusions can be reached on the role of NSAIDs in outpatient surgery.

\section{Anaesthetic choice}

The role of nitrous oxide $\left(\mathrm{N}_{2} \mathrm{O}\right)$ in postoperative nausea and vomiting has not been fully established. Studies implicating $\mathrm{N}_{2} \mathrm{O}$ as a causative factor in postoperative nausea and vomiting are matched by those refuting it as a potential cause. ${ }^{14-17}$ None of the studies examined the relationship between nausea and vomiting following laparoscopy and the day of menstrual cycle.

An increase in nausea and vomiting has been noted when laparoscopic surgery was performed during the first eight days of the menstrual cycle. ${ }^{18}$ A hormonal influence has been suggested. Oestrogen levels of women who experienced nausea and vomiting after laparoscopic ovum retrieval as well as other laparoscopic procedures are greater than for those patients who experienced no emetic symptoms. ${ }^{19}$

Local or regional anaesthesia may be an excellent choice for ambulatory surgery. Epidural anaesthesia is administered to approximately $50 \%$ of the laparoscopic procedures performed at the Virginia Mason Medical Center, Seattle, Washington. Following laparoscopy, nausea and vomiting was present in $38 \%$ of their general anaesthesia patients but in only $4 \%$ of those who had had an epidural. ${ }^{20}$

In comparing recovery following propofol for induction and maintenance with a thiopentone isoflurane anaesthetic, propofol patients were able to tolerate oral fluids sooner and there was a greater number of propofol patients who experienced no emetic symptoms. ${ }^{21}$ For those patients who experienced emetic symptoms, propofol patients were still discharged sooner than those in the thiopentone-isoflurane group.

\section{Operative procedure}

There appears to be a relationship between the incidence of nausea and vomiting and the type of surgical procedure. ${ }^{22}$ For adult patients, the occurrence of nausea and vomiting following different surgical procedures was: ovum retrieval (54\%), laparoscopy (35\%), arthroscopy (22\%), dental (16\%), D \& C (12\%).

There is a higher incidence of postoperative nausea and vomiting (up to $85 \%$ ) in paediatric patients who have strabismus surgery. Droperidol $75 \mu \mathrm{g} \cdot \mathrm{kg}^{-1} i v$ appears to be more effective when administered during induction of anaesthesia and before manipulation of the extraocular muscles than when administered shortly before the conclusion of surgery. ${ }^{23}$ A recent comparison between 20 $\mu \mathrm{g} \cdot \mathrm{kg}^{-1}$ droperidol $i v$ and $75 \mu \mathrm{g} \cdot \mathrm{kg}^{-1} i v$ concluded that both reduced vomiting compared with a control group. ${ }^{4} n$

\section{Antiemetics}

In adult patients droperidol $10-20 \mu \mathrm{g} \cdot \mathrm{kg}^{-1} i v$ immediately following induction is an effective antiemetic in 
ambulatory patients undergoing laparoscopic procedures. ${ }^{25}$ The $10 \mu \mathrm{g} \cdot \mathrm{kg}^{-1}$ dose resulted in a decrease in the severity of emetic symptoms and a shorter length of stay than a control group. Patients who recejved $20 \mu \mathrm{g} \cdot \mathrm{kg}^{-1}$ required no further treatment in the recovery room. ${ }^{26}$

Ondansetron (Zofran), a selective serotonin antagonist, appears to be an effective antiemetic without causing drowsiness or extrapyramidal symptoms. ${ }^{27}$

Neither droperidol nor metoclopramide are without side-effects. Symptoms of dysphoria, agitation, akathisia, anxiety, and acute dystonia have been reported following doses as small as droperidol $10 \mu \mathrm{g} \cdot \mathrm{kg}^{-1}$ or metoclopramide $0.15 \mathrm{mg} \cdot \mathrm{kg}^{-1}$. $^{28,29}$

\section{Postintubation croup}

For the ambulatory surgical paediatric patient we have to know not only how to treat the problem, but also how to determine when it is safe to send a treated child home.

Croup is not attributable to a single factor. ${ }^{30}$ Symptom onset varies from immediately after extubation to a maximum onset time of approximately three hours. Symptoms that will require treatment usually become evident within the first hour in the RR.

In most children croup has a benign course. In mildly symptomatic patients, oxygen and cool mist are all that may be required. A simple, inexpensive, and effective means of managing croup is with racemic epinephrine. Racemic epinephrine $0.5 \mathrm{ml} 2.25 \%$ should be diluted with $3 \mathrm{ml}$ sterile saline or water and delivered through a face mask and nebulizer. When patients receive racemic epinephrine, they should be observed in the RR for at least two hours in case of symptom recurrence. Dexamethasone and diphenhydramine $i v$ have been utilized to treat croup but neither provide relief as immediate as racemic epinephrine. Factors to be considered before a patient may be considered acceptable for discharge are:

1 Patient age. Age is a determinate of airway diameter. One millimeter of oedema impinging on the patient's airway is far more critical in a one-year-old than in a five-year-old child.

2 Severity of croup. The more severe the symptoms, the greater the chance of admission for observation.

3 Response to treatment. A rapid response to treatment without symptom recurrence are conditions for discharge to home care.

4 Prematurity. With a history of prematurity as an infant, if tracheal intubation and ventilatory support was necessary, there will be an increased incidence of subglottic stenosis.

5 Down's Syndrome. There is an increased frequency of subglottic stenosis in these patients.

6 Parent reliability. How reliable are the parents to take care of the child at home? Has there been a previous history of croup and were the parents able to manage it? Do the parents appear to be comfortable with their role at home?

7 Distance from the facility/time to access care. Distance and time are both factors. The importance of one over the other may vary from a suburban to an urban environment. Time to access care is more important than the distance one lives from emergency services.

8 Support measures. Is there a humidifier at home, and do the parents know how to use it? Do they have a telephone so that they can discuss concerns if they arise?

The answers should influence the anesthetist's decision to discharge to home care or admit for observation.

\section{Discharge criteria}

Outpatient facilities go to great length to develop criteria for patient and procedure selection; it is of equal importance to have criteria for patient discharge. The majority of psychomotor tests are too complex, time-consuming, and cumbersome to be used in a clinical setting.

Discharge of the patient should not take place until:

1 Relevant discharge criteria have been rigorously followed.

2 A responsible person is present to escort patient home.

3 Discharge instructions are discussed with both patient and responsible person and a printed copy is given to them.

4 The patient and responsible person must know how to access care in case of an emergency (telephone number of physician, facility, emergency room).

Chung et al. have developed a postanaesthetic discharge scoring system (PADS). ${ }^{31}$ Although a close correlation was noted between the scoring system and clinical criteria, more patients could be discharged earlier by using the scoring system than by relying on clinical criteria.

Patients should be informed before being discharged home that they may experience pain, headache, nausea, vomiting, dizziness and muscle aches and pains that may not be related to the incision. ${ }^{32}$ The well-informed patient will be less stressed at home if they are aware that such symptoms may occur after leaving the facility.

At Methodist Ambulatory SurgiCare patients who have had care provided by the Anesthesia Department must be accompanied home by a responsible person (physically and intellectually capable of taking care of the patient), and refrain from activities in which a decrease in alertness might be a hazard (driving a car, operating power tools, making crucial business decisions, drinking alcoholic beverages), for 24 hours. 


\section{Summary}

As more patients are provided with the compacted perioperative care that is part of outpatient surgery, the anaesthetist must assume an active role in recovery room problem solving, or we will find more patients than necessary will face unanticipated hospitalization following an outpatient procedure.

\section{References}

1 Langer JC, Shandling $B$, Rosenberg $M$. Intraoperative bupivacaine during outpatient hernia repair in children: a randomized double-blind trial. J Ped Surg 1987; 22: 267- 70.

2 Sinclair R, Cassuto J, Hogstrom S et al. Topical anesthesia with lidocaine aerosol in the control of postoperative pain. Anesthesiology 1988; 68: 895-901.

3 McGlinchey J, McLean P, Walsh A. Day case penile surgery with penile block for postoperative pain relief. Ir Med J 1983; 76: 319.

4 Tree-trakarn T, Pirayavaraporn S. Postoperative pain relief for circumcision in children: comparison among morphine, nerve block, and topical analgesia. Anesthesiology 1985; 62: 519-22.

5 Elder PT, Belman AB, Hannallah RS et al. Postcircumcision pain: a prospective evaluation of subcutaneous ring block of the penis. Regional Anesthesia 1984; 9: 48-9.

6 Wolf $A R$, Valley RD, Fear DW et al. Bupivacaine for caudal analgesia in infants and children: the optimum concentration. Anesthesiology 1988; 69: 102-6.

7 Alexander $C D$, Wetchler BV, Thompson RE. Bupivacaine infiltration of the mesosalpinx in ambulatory surgical laparoscopic tubal sterilization. Can J Anaesth 1987; 34: 362-5.

8 Andersen $R$, Krohg $K$. Pain as a major cause of postoperative nausea. Can Anaesth Soc J 1976; 23: 366-9.

9 Metter SE, Kitz DS, Young ML et al. Nausea and vomiting after outpatient laparoscopy: incidence, impact on recovery room stay and cost. Anesth Analg 1987; 66: S116.

10 Zuurmond WWA, van Leeuwen $L$. Recovery from sufentanil anaesthesia for outpatient arthroscopy: a comparison with isoflurane. Acta Anaesthesiol Scand 1987; 31: 154-6.

11 Epstein BS, Levy $M L$, Thein $M H$ et al. Evaluation of fentanyl as an adjunct to thiopental-nitrous oxide-oxygen anesthesia for short surgical procedures. Anesthesiology Review 1975; 2 : 24-9.

12 Zuurmond WWA, van Leeuwen $L$. Alfentanil $v$, isoflurane for outpatient arthroscopy. Acta Anaesthesiol Scan 1986; 30: 329-31.

13 O'Hara DA, Fragen RJ, Kinzer $M$ et al. Ketorolac tromethamine as compared with morphine sulphate for treatment of postoperative pain. Clin Pharmacol Ther 1987; 41 : 556.

14 Alexander GD, Skupski JN, Brown EM. The role of nitrous oxide in postoperative nausea and vomiting. Anesth Analg 1984; 63: A175.

15 Lonie DS, Harper NJN. Nitrous oxide anaesthesia and vomiting. Anaesthesia 1986; 41: 703-7.

16 Sengupta $P$, Plantevin $O M$. Nitrous oxide and day-case laparoscopy: effects on nausea, vomiting and return to normal activity. Br J Anaesth 1988; 60: 570-3.

17 Hovorka J, Korttila $K$, Erkola $O$. Nitrous oxide does not increase nausea and vomiting following gynaecological laparoscopy. Can J Anaesth 1989; 36: 145-8.

18 Beattie WS, Lindblad T, Buckley DN et al. The incidence of postoperative nausea and vomiting in women undergoing laparoscopy is influenced by day of menstrual cycle. Can J Anaesth 1991; 38: 298-302.

19 Beattie WS, Forrest JB, Buckley DN et al. Nausea and vomiting correlate with estrogen levels and alters dose response for droperidol. Anesthesiology 1989; 71: A957.

20 Bridenbaugh $L D$, Soderstrom $R M$. Lumbar epidural block anesthesia for outpatient laparoscopy. J Reprod Med 1979; 23: 85-6.

21 Korttila $K$, Ostman $P$, Faure E et al. Randomized comparison of recovery after propofol-nitrous oxide versus thiopentone-isoflurane-nitrous oxide anaesthesia in patients undergoing ambulatory surgery. Acta Anaesthesiol Scand 1990; 34: 400-3.

22 Pataky AO, Kitz DS, Andrews RS et al. Nausea and vomiting following ambulatory surgery: are all procedures created equal? Anesth Analg 1988; 67: S163.

23 Lerman J, Eustis S, Smith DR. Effect of droperidol pretreatment on postanesthetic vomiting in children undergoing strabismus surgery. Anesthesiology 1986; 65: 322-5.

24 Brown RE, James DJ, Weaver RG et al. Low-dose droperidol vs. standard-dose droperidol for prevention of vomiting after pediatric strabismus surgery. Anesth Analg 1990; 70: S37.

25 Wetchler $B V$, Collins $I S$, Jacob L. Antiemetic effects of droperidol on the ambulatory surgery patient. Anesthesiology Review 1982; 9: 23-6.

26 Pandit SK, Kothary SP, Pandit UA et al. Dose-response study of droperidol and metoclopramide as antiemetics for outpatient anesthesia. Anesth Analg 1989; 68: 798802.

27 Poler $S M$, Bodner $M$, White $P F$. Ondansetron is an effective new antiemetic after outpatient anesthesia. Anesthesiology 1990; 73: A18.

28 Melnick BM. Extrapyramidal reactions to low-dose droperidol. Anesthesiology 1988; 69: 424-6.

29 Caldwell $C$, Rains $G, M c K i t e r i c k K$. An unusual reaction 
to preoperative metoclopramide. Anesthesiology 1987;

67: 854-5.

30 Koka BV, Jeon IS, Andre JM et al. Postintubation croup in children. Anesth Analg 1977; 56: 501-5.

31 Chung $F$, Ong $D$, Seyone $C$ et al. A new postanesthetic discharge scoring system for ambulatory surgery. Anesth Analg 1991; 71: S42.

32 Wetchler $B V$. Problem solving in the postanesthesia care unit. In: Wetchler BV (Ed.). Anesthesia for Ambulatory Surgery (2nd ed). Philadelphia: JB Lippincott, 1991; 375- 436. 